\title{
Fermentative capacity of baker's yeast exposed to hyperbaric stress
}

\author{
Ana F. Campelo \& Isabel Belo* \\ Centro de Engenharia Biológica, Universidade do Minho, 4710-057 Braga, Portugal \\ *Author for correspondence (Fax: +351 253678986; E-mail: ibelo@deb.uminho.pt)
}

Received 6 May 2004; Revisions requested 11 May 2004; Revisions received 1 June 2004; Accepted 1 June 2004

Key words: baker's yeast, fermentative capacity, hyperbaric stress, leavening ability, Saccharomyces cerevisiae

\begin{abstract}
Baker's yeast suspensions were incubated at different pressures (from 1 bar to 6 bar) and different gases [air, $\mathrm{O}_{2}$ and a mixture of $8 \%(\mathrm{v} / \mathrm{v}) \mathrm{CO}_{2}, 21 \% \mathrm{O}_{2}$ and $\mathrm{N}_{2}$ ]. Raising the air pressure from 1 bar to 6 bar stimulated cell growth but had no effect on leavening ability or viability of the cells. A $50 \%$ reduction of the $\mathrm{CO}_{2}$ produced in dough occurred with 6 bar $\mathrm{O}_{2}$ which also stopped growth. The fermentative capacity of the cells was stimulated by the cells exposure to increased $\mathrm{CO}_{2}$ partial pressure up to 0.48 bar.
\end{abstract}

\section{Introduction}

The main function of baker's yeast (Saccharomyces cerevisiae) in the bread dough is the production of $\mathrm{CO}_{2}$ from sugars. Thus, the attainment of a high fermentative capacity is a crucial quality of the final baker's yeast. Highly aerobic culture conditions are used in the baker's yeast production to maximize the cell growth. However, traditional methods of providing high $\mathrm{O}_{2}$ transfer rates, such as the increase of stirring and air flow rates, do not prevent $\mathrm{O}_{2}$ limitation in high cell density cultures. Thus, the process of baker's yeast production usually incurs a decrease in the specific growth rate due to the limited $\mathrm{O}_{2}$-transfer capacity of industrial bioreactors. These low-specific growth rates have a negative impact on the fermentative capacity of the yeasts (van Hoek et al. 2000). Previous work has shown that the utilization of an increased pressure of air or pure $\mathrm{O}_{2}$ in the bioreactor is an effective way of improving the oxygenation of microbial cultures (Yang \& Wang 1992) and can be applied to increase baker's yeast productivity (Belo et al. 2003). Nevertheless, no attempt has been made to analyse the effect of the hyperbaric stress on the leavening ability of the cells grown under increased pressure. Several environmental stress factors have been identified as determinant to the fermentative capacity of baker's yeast, such as osmotic stress (Hirasawa \&
Yokoigawa 2001, Trainotti \& Stambuk 2001) and carbon and nitrogen starvation (Jorgensen et al. 2002, Thomsson et al. 2003).

In this work, the effect of the baker's yeast exposure to increased pressure of air, $\mathrm{O}_{2}$ and $\mathrm{CO}_{2}$ on the leavening ability of the cells was studied.

\section{Materials and methods}

\section{Hyperbaric reactor}

A stainless steel reactor Whithey 304-HDF4-300cc (Figure 1) was used to expose the yeast to hyperbaric environments and to measure the leavening ability of the cells.

\section{Yeast, media and conditions}

Commercial dried baker's yeast from DSM (Engedura) was used. Cell suspensions were prepared in the following culture medium: $5 \mathrm{~g} \mathrm{KH}_{2} \mathrm{PO}_{4} \mathrm{l}^{-1}, 2 \mathrm{~g}$ $\left(\mathrm{NH}_{4}\right)_{2} \mathrm{SO}_{4} \mathrm{l}^{-1}, 0.4 \mathrm{~g} \mathrm{MgSO}_{4} \cdot 7 \mathrm{H}_{2} \mathrm{O} \mathrm{l}^{-1}, 1 \mathrm{~g}$ yeast extract (Difco) $1^{-1}$ and $5 \mathrm{~g}$ glucose $\mathrm{l}^{-1}$. The medium was prepared in citrate buffer $50 \mathrm{mM}, \mathrm{pH}=4$. Cell suspensions of $10 \mathrm{~g}$ dry mass $1^{-1}$ were incubated for $3 \mathrm{~h}$ in the hyperbaric bioreactor at $30{ }^{\circ} \mathrm{C}, 150 \mathrm{rpm}$ at different values of pressure from 1 bar to 6 bar and gas 


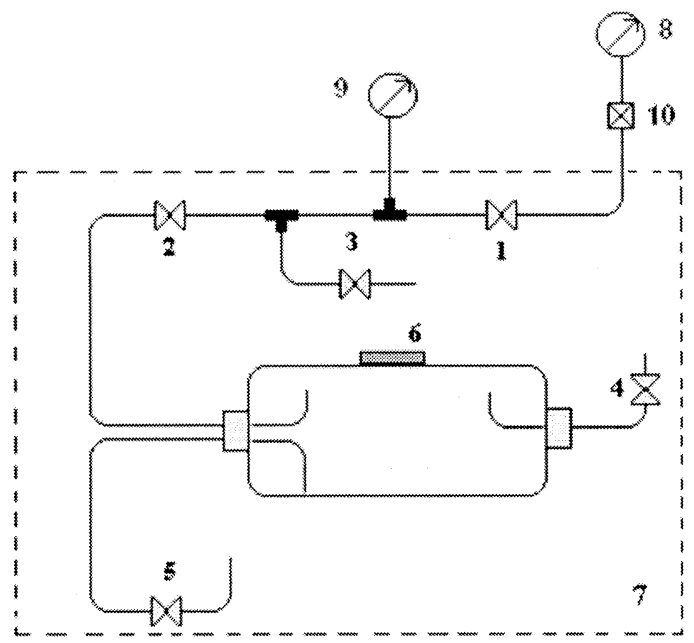

Fig. 1. Schematic representation of the hyperbaric reactor. The reactor is installed in a shaker thermostatic bath Neslab EX-600 (7) that enables agitation and temperature control. Each gas, from a gas container (8), is fed to the reactor through a gas filter of $0.45 \mu \mathrm{m}$ porosity (10) and valves 1 and 2 (Whitey SS-ORS2). The pressure of the inlet gas sets operation pressure. The pressure transducer HD 9220 Delta OHM (9) measures the total pressure inside the reactor and overpressure is released by valves 3 or 4 (Whitey SS-ORS2). The reactor was charged with the cell suspensions or with the dough mixture through the hole with sealing cap on the top (6). Liquid samples were collected through valve 5 (Whitey SS-41S2).

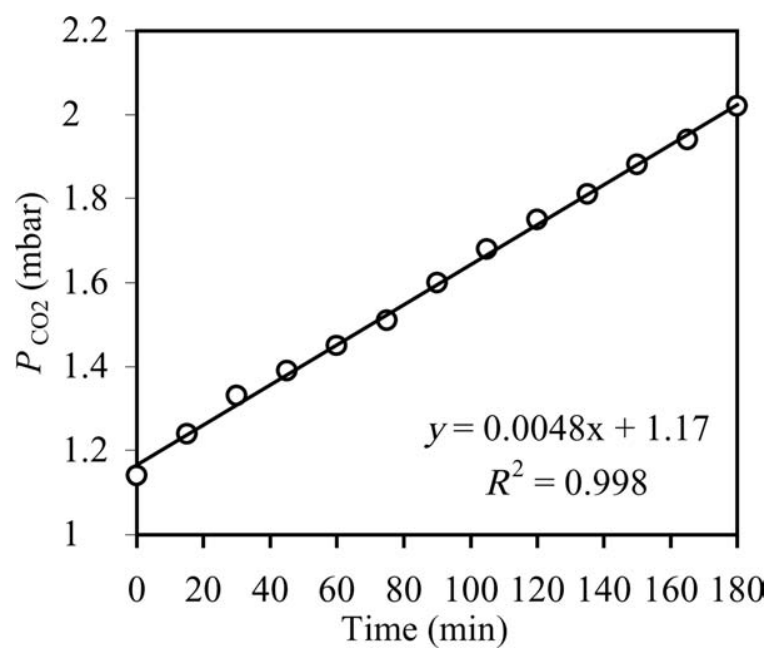

Fig. 2. Total pressure increase with time due to $\mathrm{CO}_{2}$ evolved from dough of the control assay: cells not exposed.

composition [air, $\mathrm{O}_{2}$ and a gas mixture of $8 \%(\mathrm{v} / \mathrm{v})$ $\mathrm{CO}_{2}, 21 \% \mathrm{O}_{2}$ and $\left.71 \% \mathrm{~N}_{2}\right]$.

\section{Leavening ability determination}

After incubation, yeast cells were harvested by centrifugation $(5000 \mathrm{~g}, 10 \mathrm{~min})$ washed with cold distilled water and recentrifuged. The yeast pellet was used to prepare the dough mixture. The ingredients of the dough were $100 \mathrm{~g}$ flour, $5 \mathrm{~g}$ glucose, $2 \mathrm{~g}$ yeast pellet and $62 \mathrm{ml}$ distilled water (Hirasawa \& Yokoigawa 2001). The ingredients were mixed for $15 \mathrm{~min}$ and placed into the cylindrical vessel, which was flushed with $\mathrm{N}_{2}$. The leavening ability was measured by the rate of pressure rise inside the vessel (Figure 2). The increase of pressure is proportional to the $\mathrm{CO}_{2}$ production. The pressure of carbon dioxide increased linearly with time through the analyzed period ( $2 \mathrm{~h}$ to $3 \mathrm{~h}$ ).

\section{Assays}

Cell concentration of cell suspensions was determined turbidometrically at $620 \mathrm{~nm}$ and converted to dry cell mass per litre using a previously determined correlation factor. Cell viability was estimated by the Methylene Blue staining method (Jones 1987).

\section{Results and discussion}

Incubation of baker's yeast at increased air pressure stimulated cell growth (Figure 3a). The increase of $\mathrm{O}_{2}$ availability on culture medium due to an $\mathrm{O}_{2}$ partial pressure of 1.2 bar, using air at 6 bar or pure $\mathrm{O}_{2}$ at 1.2 bar, increased the respiratory activity of the cells leading to faster growth than at low air pressure. These results are in accordance with the fed-batch growth of S. cerevisiae ATCC 32167 under hyperbaric air (Belo et al. 2003). The tolerance of $\mathrm{O}_{2}$ toxicity up to $1.2 \mathrm{bar}$ of baker's yeast was also shown by the insignificant difference ( $95 \%$ confidence level) in the viability of cells exposed to air at 1.2 bar and 6 bar, and to 1.2 bar of pure $\mathrm{O}_{2}$ (Figure $3 b$ ).

According with the results in Figure 4, it is clear that is not the total pressure up to 6 bar, alone, that affects the leavening ability of baker's yeast. The $\mathrm{CO}_{2}$ production rates in dough with baker's yeast exposed to air at 1.2 bar and 6 bar were quite close to the value obtained with cells not exposed (control). Thus, a 1.2 bar partial pressure of $\mathrm{O}_{2}$ did not affect the leavening power of the cells. This was also confirmed by the experiment with 1.2 bar of pure $\mathrm{O}_{2}$.

Also, the leavening ability of the cells was kept unchanged by the exposure to a hyperbaric environment of 6 bar of a mixture containing $8 \%(\mathrm{v} / \mathrm{v}) \mathrm{CO}_{2}, 21 \%$ $\mathrm{O}_{2}$ and $\mathrm{N}_{2}$ compared to the control, despite reduction in cell growth and viability. Thus, the increase of $\mathrm{CO}_{2}$ partial pressure up to 0.48 bar that can be attained 

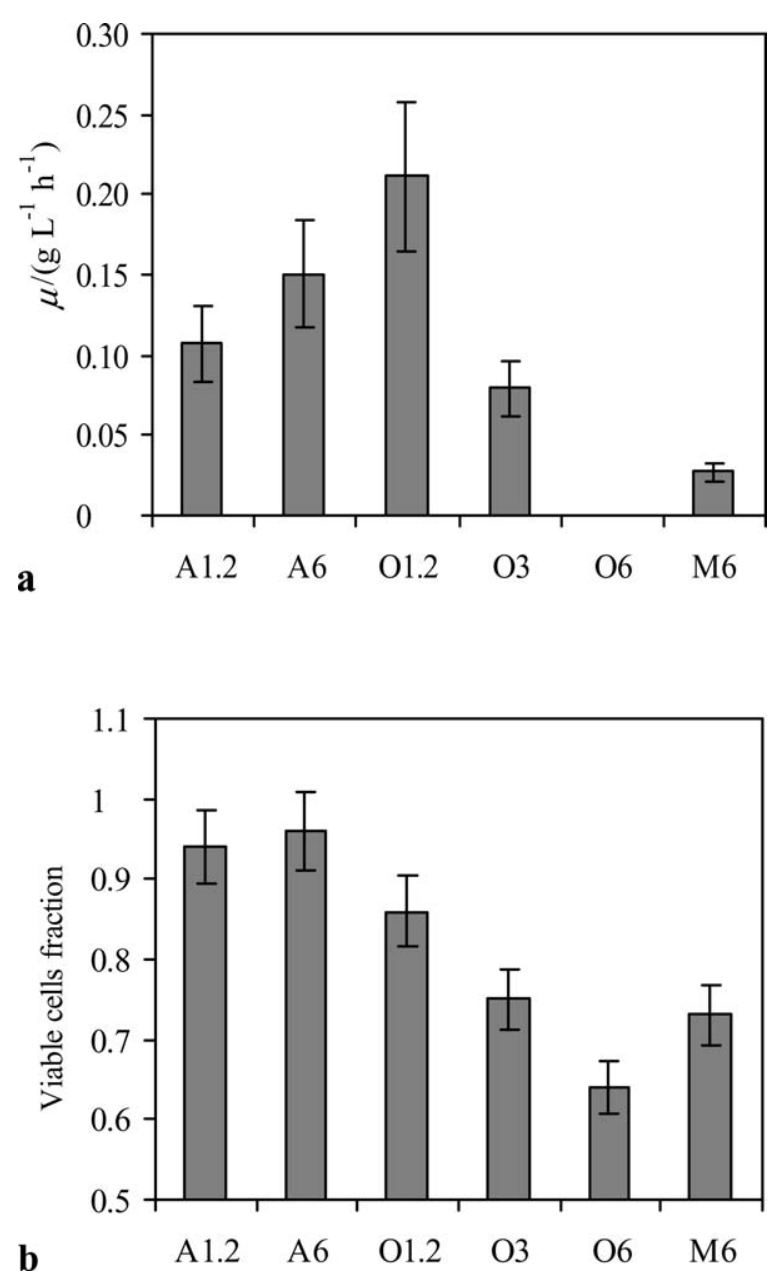

Fig. 3. Effect of gas pressure exposure for $3 \mathrm{~h}$ on the specific cell growth rate (a) and on the final fraction of viable cells (b) of baker's yeast. Condition labels: $\mathrm{A}-$ air, $\mathrm{O}-\mathrm{O}_{2}$ and $\mathrm{M}-$ gas mixture with $8 \% \mathrm{CO}_{2}$. Numbers in labels are pressure values (bar). Data are means $\pm 95 \%$ confidence interval.

in yeast cultivation with hyperbaric air, will not have a significant impact on the fermentative capacity of baker's yeast.

When the hyperbaric incubation of cells was carried out with pure $\mathrm{O}_{2}$ above 1.2 bar, growth, however, was drastically inhibited at 3 bar and completely stopped at 6 bar.

Previous work reported 8 bar of pure $\mathrm{O}_{2}$ as a limit pressure for cellular growth of $S$. cerevisiae ATCC 32167 (Pinheiro et al. 1997). Here we found baker's yeast slightly sensitive to $\mathrm{O}_{2}$ pressure.

Toxicity of $\mathrm{O}_{2}$ affected the leavening ability of baker's yeast, since $\mathrm{CO}_{2}$ production rate decreased by $36 \%$ and $54 \%$, for $\mathrm{O}_{2}$ pressure of 3 bar and 6 bar,

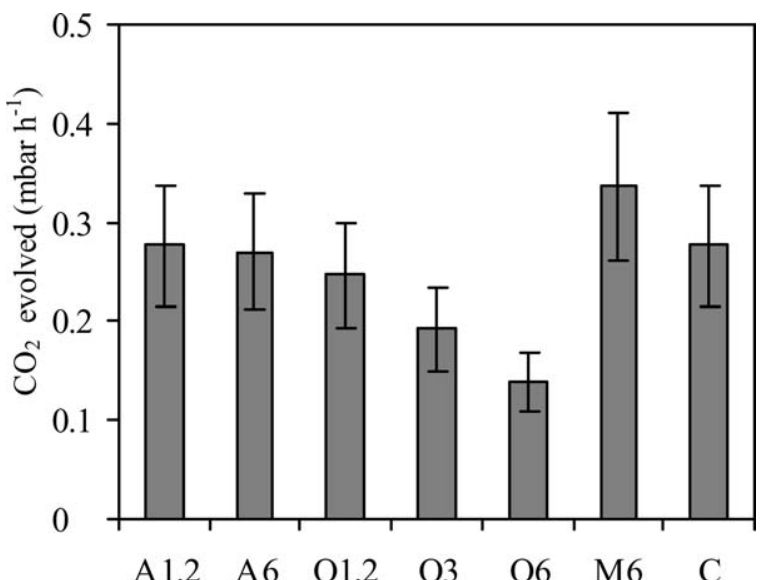

Fig. 4. Effect of gas pressure exposure of baker's yeast for $3 \mathrm{~h}$ on the rate of $\mathrm{CO}_{2}$ evolution in bread dough in an anaerobic environment. Condition labels: $\mathrm{A}-$ air, $\mathrm{O}-\mathrm{O}_{2}, \mathrm{M}-$ gas mixture with $8 \% \mathrm{CO}_{2}$ and $\mathrm{C}$ refers to the control assay (cells not exposed). Numbers in labels are pressure values (bar). Data are means $\pm 95 \%$ confidence interval.

respectively, compared to the experiment with 1.2 bar $\mathrm{O}_{2}$ pressure.

Cell viability was reduced 1.34 -fold by the increase in $\mathrm{O}_{2}$ pressure from 1.2 bar to 6 bar, indicating that cell membrane is also affected by $\mathrm{O}_{2}$ stress. This could have implications in sugars transport across the membrane, which has been reported has the major metabolic step affected by other stresses, such as $\mathrm{NaCl}$ stress (Trainottti \& Stambuk, 2001, Rossel et al. 2002). On the other hand, $\mathrm{O}_{2}$ effect on the leavening ability of yeasts could be an indirect effect of $\mathrm{O}_{2}$ toxicity in cell growth, according with the reported influence of specific cell growth rate in the fermentative capacity of yeasts (van Hoek et al. 2000).

Further work is being carried on to identify the mechanisms of $\mathrm{O}_{2}$ pressure effect on leavening ability of baker's yeast and to compare the baker's yeast response to other types of stress. Nevertheless, with the work here reported it is possible to conclude that hyperbaric air up to pressures of 6 bar, or pure $\mathrm{O}_{2}$ up to $1.2 \mathrm{bar}$, can be applied for the aeration improvement of high cell density cultures of baker's yeast without affecting the fermentative capacity of the final product. The use of $\mathrm{pO}_{2}$ above 1.2 bar is limited by the toxicity effects of $\mathrm{O}_{2}$, which negatively affects the leavening power of baker's yeast. 


\section{References}

Belo I, Pinheiro R, Mota M (2003) Fed-batch cultivation of Saccharomyces cerevisiae in a hyperbaric bioreactor. Biotechnol. Prog. 19: 665-671.

Hirasawa R, Yokoigawa K (2001) Leavening ability of baker's yeast exposed to hyerosmotic media. FEMS Microbiol. Lett. 194: 159162.

Jones RP (1987) Measures of yeast death and deactivation and their meaning: part I. Process Biochem. 118-128.

Jorgensen H, Olsson L, Ronnow B, Palmqvist EA (2002) Fed-batch cultivation of baker's yeast followed by nitrogen or carbon starvation: effects on fermentative capacity and content of trehalose and glycogen. Appl. Microbiol. Biotechnol. 59: 310-317.

Pinheiro R, Belo I, Mota M (1997) Physiological behaviour of Saccharomyces cerevisiae under increased air and oxygen pressures. Biotechnol. Lett. 19: 703-708.
Rossel S, van der Weijden CC, Kuckeberg A, Bakker BM, Westerhoff HV (2002) Loss of fermentative capacity in baker's yeast can partly be explained by reduced glucose uptake capacity. Mol. Biol. Reports. 29: 255-257.

Thomsson E, Larsson C, Albers E, Nilsson A, Franzén CJ, Gustafsson L (2003) Carbon starvation can induce energy deprivation and loss of fermentative capacity in Saccharomyces cerevisiae. Appl. Env. Microbiol. 69: 3251-3257.

Trainotti N, Stambuk BU (2001) NaCl stress inhibits maltose fermentation by Saccharomyces cerevisiae. Biotechnol. Lett. 23: 1703-1707.

van Hoek P, de Hulsteret E, van Dijken JP, Pronk JT (2000) Fermentative capacity in high-cell-density fed-batch cultures of baker's yeast. Biotechnol. Bioeng. 68: 517-523.

Yang JD, Wang NS (1992) Oxygen mass transfer enhancement via fermentor headspace pressurization. Biotechnol. Prog. 8: 244251. 